Prepared for the U.S. Department of Energy

under Contract DE-AC05-76RL01830

\title{
Establishment of Northwest Building Testbeds: Final Progress Report
}

\author{
DL Stiles
}

August 2012

Pacific Northwest

NATIONAL LABORATORY

Proudly Operated by Battelle Since 1965 



\title{
DISCLAIMER
}

This report was prepared as an account of work sponsored by an agency of the United States Government. Neither the United States Government nor any agency thereof, nor Battelle Memorial Institute, nor any of their employees, makes any warranty, express or implied, or assumes any legal liability or responsibility for the accuracy, completeness, or usefulness of any information, apparatus, product, or process disclosed, or represents that its use would not infringe privately owned rights. Reference herein to any specific commercial product, process, or service by trade name, trademark, manufacturer, or otherwise does not necessarily constitute or imply its endorsement, recommendation, or favoring by the United States Government or any agency thereof, or Battelle Memorial Institute. The views and opinions of authors expressed herein do not necessarily state or reflect those of the United States Government or any agency thereof.

\author{
PACIFIC NORTHWEST NATIONAL LABORATORY \\ operated by \\ BATTELLE \\ for the \\ UNITED STATES DEPARTMENT OF ENERGY \\ under Contract DE-AC05-76RL01830
}

Printed in the United States of America
Available to DOE and DOE contractors from the Office of Scientific and Technical Information,
P.O. Box 62, Oak Ridge, TN 37831-0062;
ph: (865) 576-8401
fax: $(865)$ 576-5728
email: reports@adonis.osti.gov

\begin{abstract}
Available to the public from the National Technical Information Service, U.S. Department of Commerce, 5285 Port Royal Rd., Springfield, VA 22161 ph: (800) 553-6847 fax: $(703) 605-6900$ email: orders@ntis.fedworld.gov online ordering: http://www.ntis.gov/ordering.htm
\end{abstract}

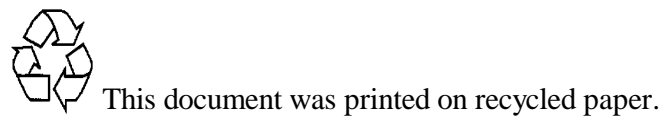




\title{
Establishment of Northwest Building Testbeds: Final Progress Report
}

\author{
Office of Energy Efficiency and Renewable Energy \\ Building Technologies Program
}

PNNL Project Manager: Mr. Dennis Stiles

HQ Technology Development Manager: Ms. Arah Schuur

DL Stiles

August 2012

Prepared for the U.S. Department of Energy

under Contract DE-AC05-76RL01830

Pacific Northwest National Laboratory

Richland, Washington 99352 


\section{Introduction}

The Northwest Building Testbed project established a set of 101 single-family residential buildings that are fully metered to acquire data on residential energy usage. These 101 occupied homes were recruited with two objectives in mind. First, to compile detailed end use data for a period of at least two years (calendar years 2012 and 2013), providing up-to-date information about residential energy consumption and load characteristics. Secondly, it is hoped that in the future these homes can be used to evaluate various energy efficiency technologies and/or program strategies, with a minimum of one year's metering data providing a baseline for comparison with post-modification/intervention energy consumption.

The project was jointly funded by the U.S. Department of Energy (DOE) - Building Technologies Program (BTP), and the Northwest Energy Efficiency Alliance (NEEA). The project was jointly directed by NEEA and the Pacific Northwest National Laboratory (PNNL), beginning in October 2010 and concluding with completion of metering system installation in December 2011. NEEA will continue to collect data from these homes through the end of calendar year 2013 (at a minimum) and during the 20122013 timeframe will provide periodic data reports, facilitate access to the database by DOE and others, and develop protocols for recruiting homeowners to participate in energy efficiency research projects.

This document summarizes the outcomes achieved in the jointly-funded project, describes major project activities, discusses future plans for the homes and data, and provides details on project costs and schedule performance. This summary document emphasizes BTP programmatic interests and is a companion to a recently published report prepared for NEEA (Larson et al) that provides greater detail on the technical approach to metering and data management, and that provides an interim report on the types of data being acquired from the metered homes.

\section{Project Outcomes}

This project installed comprehensive energy end use metering systems in 101 homes across the Pacific Northwest region, enabling detailed collection of energy consumption data. The 101 homes are drawn from a larger sample (1400 homes) that is statistically representative of the residential building stock in the Pacific Northwest region of Washington, Oregon, Idaho and Western Montana. While the small sample size and the process of recruitment means that the set of 101 homes does not maintain statistical integrity, these homes are believed to be representative of the regional building stock. Further, the distribution of the 101 homes across the region, as shown in Table 1, is representative of regional climatic diversity which ranges from moderate summer and winter temperatures in Western Washington and Oregon (where peak energy consumption is limited to a short and mild winter), to the arid areas of Eastern Washington (where peak consumption coincides with a hot and dry summer) and the mountainous areas of Idaho and Montana that experience very cold winters and warm summers. Further, the geographic distribution of the homes provides good representation for areas served by both investorowned and public utilities, which is important for future use of the data in more effectively targeting utility-managed efficiency programs.

Table 1. Distribution of Metered Homes Within the Northwest

\begin{tabular}{|l|r|}
\hline Region & Total \\
\hline Puget Sound area of Washington & 36 \\
\hline Western Oregon & 30 \\
\hline Eastern Washington & 16 \\
\hline Idaho & 14 \\
\hline Western Montana & 5 \\
\hline
\end{tabular}


After securing homeowner agreement to participate in the project, each home was characterized (age, lot orientation, construction, etc.), a home energy audit was conducted, and a survey was completed to collect occupant information (number of occupants, occupations, commute patterns, etc.). Comprehensive metering systems were then installed to monitor power consumed at the whole home level, indoor and outdoor temperature, and energy consumption for the following end uses:

- Well pumps, spas and other major electric loads

- Heating and cooling systems (19 electric resistance, 25 heat pumps, 57 natural gas)

- Domestic hot water (60 electric, 39 natural gas, 2 central boilers)

- Appliances, including refrigerators, freezers, dishwashers, clothes washers and dryers, and ranges. In total, 123 refrigerators and 46 freezers are metered.

- Electronic plug loads, including televisions, DVD players, cable boxes, gaming consoles, computers, computer peripherals, and space heaters. 160 televisions are metered.

- $\quad$ Lighting (1,900 lighting loggers are installed)

A number of singular specialty appliances are also metered, including a wine refrigerator, an elliptical exercise system, one large tropical fish tank and one charging station for a Nissan Leaf.

Each of the home metering systems are connected to a central database through a secure cellular data network. Ongoing maintenance and analysis of the data will be supported by NEEA through 2013, with periodic reports made available reporting on data accumulation and providing observations on end use characteristics. After at least one full year of data has been acquired, an aggregated database with all personally identifiable information removed will be made available to DOE, academia, and utilities.

\section{Project Approach}

This project was designed to capitalize upon the 2011 Residential Building Stock Assessment (RBSA), an extensive study completed by NEEA periodically to support the Northwest power planning process (see NPCC 2010). The RBSA study uses a rigorous process to develop a representation of the residential building population in the Pacific Northwest region (Washington, Oregon, Idaho and Western Montana). PNNL and NEEA recognized that the statistically representative sample developed in the RBSA could serve as a pool from which homeowners could be recruited to participate in a metering program resulting in an extensive database of consumption patterns inmodern homes with modern appliances. This new database would provide a significant update to regional studies conducted in the 1980s (Pratt, 1989) and be a significant addition to the data available to researchers nationally as well. Further, PNNL and NEEA researchers believed that the recruited homeowners could form a pool interested in participating in future activities, including testing energy-efficient appliances, performing energy efficiency retrofits, or human behavior studies. The following section provides a summary of the RBSA ${ }^{1}$, the process used to recruit participants for this project, the sub-metering protocol used in this project, and the system developed to acquire and archive data.

\section{Residential Building Stock Assessment}

The RBSA is statistically designed to collect energy use characteristics over a large and diverse sample (in excess of 1,400 sites) with the goal of providing statistically valid representation of the region's residential populations (with suitable statistical weightings and confidence interval limitations). The RBSA was based upon a staged random sample of the population of households in each of seven subregions (divided between public power utilities and investor-owned utilities) that were designed to

\footnotetext{
${ }^{1}$ The RBSA was not part of the scope of the DOE-funded project, but provides a critical foundation for this project.
} 
distinguish differences in climate and other features within the larger region. The first stage used a phone survey organized around a random selection of utility customer records where such records were available. The remaining areas were called using random digit dialing for both land lines and cellular phones. The phone survey was administered to all willing participants. Each sampling area was assigned a target so that the required samples were collected with the distribution required across the region. Each completed survey was catalogued as a "complete" and became the sampling frame for the next phase of the RBSA. The second stage used the phone survey to identify residences that would be targeted for a detailed characteristics audit that was integral to RBSA data collection. In this second stage, personnel visited approximately 500 homes to validate survey information, collect additional information about building characteristics for each housing type (single-family, multi-family, manufactured home), collect information about major energy systems, and test whole-home and ducting tightness. These data then form the basis for a number of estimates of the energy efficiency potential within the region's residential buildings. The RBSA was completed throughout calendar years 2010/11 and is followed by a comparable study focusing on the region's commercial buildings (the commercial building stock assessment - CBSA), planned for completion by the end of calendar year 2012.

\section{Homeowner Recruitment for Metering}

The RBSA sample frame of approximately 1,400 surveyed and 500 audited homes formed the basis for recruiting participants to the metering program, beginning with a randomized telephone survey to contact homeowners from the RBSA sample pool. Based upon initial responses, participants in the phone survey were subsequently contacted for recruitment to the metering project. Homeowners were offered incentives totaling $\$ 500$ to $\$ 700$ to participate in the project, with an up-front payment of $\$ 200$ to $\$ 300$ and annual incentives of $\$ 150$ to $\$ 200$ thereafter. The incentives were offered to compensate homeowners for the inconvenience of having workers in the home to install the sub-metering system and subsequent visits for maintenance, as well as reward their willingness to share information about their energy consumption. All participants were assured of privacy during data analysis and reporting. The homeowner agreement form is included as Attachment 1 to this document. (Note: PNNL submitted the recruitment and metering plans for review counsel and PNNL's institutional review board to ensure that all human subject considerations were identified and addressed; no concerns were identified.)

\section{Metering Approach}

The goal of the project was to ensure comprehensive collection of energy consumption data for all significant end uses in the home. PNNL and NEEA contracted with Ecotope Incorporated to develop the metering protocol for the recruited homes, which is included as Attachment 2 to this document. The metering protocol was extensively reviewed by PNNL and NEEA buildings experts and was tested in two homes owned by NEEA personnel prior to implementation.

Individual meters were used to record indoor and outdoor temperature, cumulative energy use, and instantaneous power, power factor, and voltage for all of the following end uses:

- Whole home (at service entry)

- Well pumps, spas and other major electrical loads

- Heating and cooling systems

- Domestic hot water ${ }^{2}$ systems

\footnotetext{
${ }^{2}$ For gas hot water units the on/off state of the unit was monitored and energy consumption was imputed based upon a one-time measurement of combustion efficiency. A similar approach was employed for gas furnaces.
} 
- Appliances, including refrigerators, freezers, dishwashers, clothes washers and dryers, and cooking ranges, as well as single unit specialty appliances (a wine storage unit, an exercise unit, a large tropical fish tank, and a charging station for a Nissan Leaf).

Individual meters were also used for miscellaneous plug loads, including electronics such as televisions, DVD players, cable boxes, gaming consoles, computers, computer peripherals, space heaters and similar devices. Small resistance loads such as toasters, microwaves, or clocks were excluded because they do not represent a significant power draw. Measurements are taken every five minutes and data logged by the individual meters are uploaded to the central data servers daily.

Lighting was treated differently than other loads, with metering focusing on those lights that are used most frequently, rather than comprehensive metering. On average, $80 \%$ of the lighting fixtures and lamps in the homes are metered. In addition, the lighting loggers are not networked and do not communicate automatically with the central data servers. Instead, the lighting loggers are leave-behind devices that record changes of state (from on to off, etc.) and the light wattage. Approximately 1,900 lighting loggers were installed as part of the project and the data from these units are retrieved annually by technicians.

\section{Data Management}

Metering data are collected through a secure home network (virtual private network - VPN) that includes two firewalls. The gateway from each home to the central server is a $3 \mathrm{G}$ cellular router, which connects to the central network via a private cellular data network with redundant VPN routers and a secure firewall. Because this is a cellular data network and not a telephone network, the connections are always live, enabling continuous monitoring of all equipment in the network. Further, this private network offers no access to the public Internet, adding a key level of protection of homeowner privacy.

Raw sensor data is automatically checked for a variety of quality parameters (e.g., out of range values) and daily quality reports are reviewed by system analysts. Once acquired by the central data servers, additional redundant data quality checks are executed as collapsed data files are created. Routine quality spot checks are also conducted, in which analysts randomly select sites, sensors, and data streams for review. Data quality measures have also been developed for the lighting data, which are retrieved and reviewed manually. A thorough description of the data network architectures and data quality programs can be found in the companion interim data report (Larson et al).

\section{Future Plans and Possibilities}

The NEEA budget funds maintenance of the metering system, data collection, and database maintenance through the end of calendar year 2013, at which time a full report of the aggregated data will be published. Interim reports will be made available, presenting selected case studies of particular interest; the first interim report (Larson et al) is a companion to this document. These maintenance and data collection/reporting activities may be extended for up to three additional years with approval of the NEEA board, depending upon cost and the level of interest in the data collected.

At a minimum, this project will develop a new data set suitable for use by researchers seeking to understand modern residential energy consumption or to validate building energy models and to utilities seeking to develop new load profiles or more effectively target energy efficiency programs. NEEA is working with a steering committee, which includes PNNL researchers, to determine when and how a version of the database with all personally identifiable information removed can be shared with DOE, utilities, researchers and other interested parties. The policies and procedures for gaining access to the database are expected to be released in the first quarter of 2013. 
In addition to providing data on current energy consumption patterns, PNNL and NEEA envisioned that the 101 homes, with one full year of data as an energy consumption baseline, would be ideal for testing new technologies (e.g., heat pump hot water heaters, energy-efficient appliances, non-intrusive load monitoring systems, etc.), evaluating the real-world cost-benefit considerations for efficiency retrofit measures, or undertaking consumer behavior research. It is our expectation that a significant fraction of the homeowners participating in the current program would have a higher-than-average willingness to participate in such programs. Having an established testbed with a meaningful, detailed energy consumption baseline (at least one year's worth of data) could significantly accelerate energy efficiency research and deployment of measures that can meet regional or national energy efficiency goals. Toward that end, NEEA is convening a steering group that will develop protocols for evaluating, prioritizing, and implementing such research and evaluation projects in these 101 homes, following one full year of data collection. These research and evaluation projects would require new funding from NEEA, utilities, or some other source.

With NEEA's CBSA (Commercial Building Stock Assessment) planned for completion in late 2012, it may be of interest to DOE to assess whether a comparable project could create a sample set of metered commercial buildings. The CBSA follows a rigorous process to develop an inventory of commercial buildings across the Pacific Northwest and collects significant amounts of data characterizing many buildings within each of the building types defined by NEEA. (In fact, more survey and characterization effort goes into the CBSA than into the RBSA, as the Northwest Power Planning Council assessments have shown that there is greater energy efficiency potential in commercial buildings than in residential.) While it would not be realistic to meter a sample that is representative of all commercial buildings, it would certainly be feasible to address a representative set within one or two building types, depending upon which building types are of greatest importance to DOE. For example, NEEA has expressed nearterm interest in getting detailed consumption data for medium-scale office and "big-box" retail buildings, with longer-term interest in clinical and small-scale office buildings.

\section{Project Cost and Schedule Summary}

The DOE contribution to this project began in October 2010 and continued through January 2012 when installation of the sub-metering systems in all 101 homes was completed and acquisition of data to the central database was fully operational for all 101 homes. The total cost of the jointly funded project was $\$ 2.1 \mathrm{MM}$ and DOE provided $\$ 750,000$ for the project, of which $\$ 725,000$ was expended. NEEA has budgeted an additional $\$ 700,000$ for system maintenance, continued data acquisition, and reporting through the end of CY 2013; no DOE funds have been directed toward those efforts.

The DOE funds supported the labor associated with project planning, project management, developing the sub-metering protocol, homeowner recruitment, and meter installation. NEEA funded acquisition of the metering equipment systems, development of the data acquisition system and the central database, all legal fees associated with developing the homeowner agreements, and all incentives provided to the homeowners. Procurement of the hardware by NEEA ensured that the property could remain in the homes indefinitely, which could not have been the case if DOE funds were used for the procurement. Further, the decision to assign "ownership" of the database to NEEA was a deliberate one, as NEEA had funds available to support long-term database maintenance while DOE funding would be dependent upon congressional appropriations and programmatic priorities. (In order to cover the full costs of the project, Bonneville Power Administration (BPA) and Avista Corporation, two leading NEEA members, contributed $\$ 600,000$ to supplement the NEEA budget for CY11/12/13.)

First funding was received from DOE in October 2010 and PNNL launched the project in November. The first three milestones were completed as scheduled in the original statement of work (SOW) filed with DOE: 
- Residential sampling methodology defined

completed 12-01-2010

- Protocol for gathering field characteristics defined

completed 01-30-2011

- Sub-metering protocols and sampling methodology developed

completed 01-30-2011

With consent of DOE, the remaining milestones associated with the DOE-funded work scope were rescheduled to better coincide with NEEA's schedule for completion of the RBSA (the original project plan submitted to DOE reflected the federal fiscal year, whereas NEEA's fiscal year coincides with the calendar year and the RBSA schedule reflected that budget cycle). All critical path revised milestones were successfully met. One milestone was delayed three months, but this milestone was not a critical path activity and did not impact the overall project schedule. The project milestones, with the revised planned date shown in parentheses, are listed below:

- Homeowner recruitment complete (09-30-2011)

completed 12-30-2011

- Sub-meter installation initiated (10-01-2011)

initiated 10-01-2011

- Sub-meter installation complete (12-31-2011)

completed 12-30-2011

- Data collection initiated (11-30-2011)

initiated 10-30-2011

NEEA completed the RBSA in the summer of 2011 and began recruiting homeowners in October. All sub-metering systems were installed in the 101 homes according to the revised schedule and data acquisition was successfully initiated in October 2011.

\section{References}

Larson, Ben et al. June 25, 2012. "Residential Building Stock Assessment Metering Study: Interim Report." Prepared for the Northwest Energy Efficiency Alliance.

NPCC 2010. "Sixth Northwest Conservation and Electric Power Plan." Northwest Power and Conservation Council, Portland, Oregon. Council Document 2010-09.

Pratt, Robert G., C.C. Conner, E.E. Richman, K.G. Rigland, W.F. Sandusky, M.E. Taylor, 1989. "Description of Electric Energy Use in Single-Family Residences in the Pacific Northwest, EndUse Load and Consumer Assessment Program." Prepared for the U.S. Department of Energy under contract DE-AC06-76RL0 1830. 


\section{ATTACHMENT 1}

\section{Homeowner Metering Participation Agreement \\ RESIDENTIAL BUILDING STOCK ASSESSMENT \\ METERING STUDY \\ Participation Agreement}

The Northwest Energy Efficiency Alliance, Inc. ("NEEA") is sponsoring a regional study to measure and analyze the energy use and performance of homes (the "Study"). NEEA has contracted with Ecotope, Inc. to help implement the Study. Your residence (the "Residence" which is located at the address provided below) has been selected to participate in the Study. By signing this agreement, you (the "Participant") agree to participate in the Study and agree to the following terms and conditions (the "Agreement"):

1. Summary: As part of the Study, Participant will allow NEEA and its designated contractor to install metering equipment (the "Equipment") and collect energy usage data in the Residence for the term of this Agreement. More information on the Study can be found at http://neea.org/wholehomestudy.

2. Term: This Agreement will begin on the date of Participant's signature below and will end 24 months after installation of the Equipment in the Residence, unless this Agreement is terminated or modified as described in Sections 11 and 13 below.

3. Incentive: In exchange for Participant's full participation in the Study, Participant will receive

$\$$ after installation and $\$$ for every year of participation under this

Agreement thereafter.

4. Equipment: Participant agrees to allow NEEA and its designated contractor to install the Equipment in the Residence as is necessary to complete the Study. Participant will not remove, disconnect or tamper with Equipment and will notify NEEA if the Equipment is damaged or otherwise does not appear to be functioning correctly. All Equipment shall be owned by NEEA and will be removed by NEEA or its designated contractor after the term of this Agreement.

5. Access to Residence and Evaluation: Participant agrees to provide NEEA and its designated contractor reasonable access to the Residence to access data, and maintain, replace, add, remove or evaluate Equipment. Participant agrees to have an adult present when NEEA or its designated contractor is at the Residence. Participant represents that Participant is lawfully able to perform all obligations of the Participant under this Agreement and will notify NEEA if they sell, lease, transfer or otherwise no longer reside in the Residence during the term of this Agreement.

6. Insurance: Through the term of this Agreement, NEEA and its designated contractor shall carry commercial general liability insurance with a minimum single limit of at least $\$ 1,000,000$, and Participant shall maintain reasonable and adequate home insurance coverage of the Residence.

7. Information: NEEA will treat all personal information of Participant, including energy usage data, as confidential and will use it only as necessary to complete and evaluate the Study. Participant information will be released to the public in aggregate without identifying characteristics of the Participant. Participant authorizes NEEA and its designated contractor to access energy usage data of the Participant by accessing the electric utility accounts for the Residence. Participant agrees to provide reasonable assistance to NEEA and its designated contractor to obtain such information.

8. Materials: All new materials, information, property and other items accumulated or developed by NEEA or its designated contractor in connection with this Agreement shall belong exclusively to NEEA.

9. Indemnification: NEEA (including its designated contractor) and Participant shall indemnify each other from any and all claims, demands, suites, loses, costs, and damages of every kind and description, including reasonable attorney fees, resulting or arising from any act of the indemnifying party.

10. DISCLAIMER: NEEA does not guarantee any advice, analysis, and guidance provided by NEEA or its designated contractor under this Agreement.

RSBA Metering Participation Agreement - 1 
11. Termination: NEEA may terminate this Agreement at any time, for any reason, upon thirty (30) days written notice to the Participant. Upon termination, Participant shall allow NEEA to recover all Equipment located in the Residence and access to all Participant data accumulated up until the termination date. If the termination is not a result of Participant's breach or default, a percentage of the incentive shall be paid to the Participant equal to the percentage of days Participant participated in the Study.

12. Notice: Any notice under this Agreement shall be in writing and shall be delivered in person or mailed, properly addressed and stamped with the required postage to the addresses specified at the end of this Agreement.

13. No Waiver; Changes; Exclusive Agreement: The failure of NEEA or Participant to exercise or enforce any provisions or rights under this Agreement shall not operate as a waiver of their right to exercise or enforce such provisions or rights in that or any other instance. Changes to this Agreement may only be made by a written amendment signed by both NEEA and Participant. This Agreement may not be orally modified. This Agreement sets forth the entire agreement between NEEA and Participant with respect to the subject matter contained herein and supersedes all prior or contemporaneous oral or written agreements or understandings between NEEA and Participant regarding such subject matter.

14. Disputes and Jurisdiction: All claims arising out of this Agreement and disputes not settled between NEEA and Participant shall be settled by binding arbitration in accordance with the then effective rules of the Arbitration Service of Portland, Inc. Participant irrevocably submits to the exclusive jurisdiction of the Multnomah County Circuit Court or the United States District Court in Portland, Oregon, over any suit, action or proceeding arising out of or relating to this Agreement, and confirms that such court shall have personal jurisdiction over Participant.

15. Assignment: Neither party shall assign this Agreement or any right or interest in this Agreement without the prior written consent of the other Party, which shall not be unreasonably witheld. This Agreement shall by fully binding upon, inure to the benefit of, and be enforceable by the successors, permitted assigns and legal representatives of Participant and NEEA.

16. Severability and Survival: If any provision of this Agreement shall be held illegal, invalid, or unenforceable, the remaining provisions of this Agreement shall remain in full force and effect. All obligations of Participant and of NEEA that may reasonably be interpreted or construed as surviving the completion, term ination or cancellation of this Agreement shall survive the completion, termination or cancellation of this Agreement.

Northwest Energy Efficiency Alliance, Inc.

Dave Kresta

Sr. Manager for Product Development, Emerging Technology

Date: _September 28,2011

Address for Notices:

Northwest Energy Efficiency Alliance, Inc.

421 SW $6^{\text {th }}$ Ave., Suite 600

Portland, OR 97204

PH:503-688-5400 FAX:503-688-5447

RSBA Metering Participation Agreement - 2

\section{Participant}

Signature

Printed Name

Date:

Phone:

Address of Residence: 


\section{ATTACHMENT 2}

\section{Metering Insallation Protocol}

RBSA Metering

Metering Installation Protocol
ECDTDPE

CONSULTING

RESEARCH

DESIGN

Prepared For:

Northwest Energy Efficiency Alliance

Prepared By:

Ecotope, Inc.

September 19, 2011

Revised: March 2, 2011 


\section{Overview}

This document describes Ecotope's approach to selecting and metering energy loads in the home.

We will meter the majority of the end-uses in the home. We will meter the central heating/cooling system, the water heater, plus any other major appliances that have a dedicated circuit (such as a dishwasher or clothes dryer) at the panel. Other major appliances plus some electronics will be measured with decentralized plug load meters which communicate wirelessly with a central router that will send all data via cellular connection to a central server. Gas furnace and water heater use will be measured with current-sensing state sensors. The signal from these control state circuits, indicating overall run-time, will be combined with gas flow measurements taken during the installation process. This will allow assessment of gas usage at various appliances. The system will also meter electric usage of these heating systems, particularly fans. A selection of lighting fixtures will be monitored with standalone dataloggers for time of use; these data will be combined with fixture and room wattages to determine overall usage.

\section{Equipment Measured}

For equipment metered at the panel, we will get accumulated true RMS energy and 5-minute snapshots of true power $(\mathrm{kW})$, apparent power $(\mathrm{kVA})$, reactive power (kVAR) and voltage. Our meter/logger equipment for dedicated circuits will measure instantaneous values each logging period. The plug-load meter will log accumulated true RMS energy and instantaneous snapshots of true power and power factor every 5 minutes. For gas equipment, we will track cumulative use and use per logging period. Data will be logged every five minutes with the exception of indoor temperature, where hourly data will provide sufficient resolution. This should provide the resolution needed to assess energy use and load shapes.

The whole house load will be metered using the sum of two measurements, each 120 VAC to neutral, for both sides of the panel. All other loads are expected to be single phase.

The following table includes the types of equipment that may be monitored in this study. Note that this list does not imply that all of these end-uses will be metered. For example, not all appliances, plug-loads or lighting fixtures will be metered. The overall objectives and on-site selection strategies for precisely which end uses will be metered is included after the table in the Section 3. 
Equipment

Service entry (all electricity to home)

HVAC

Heat pumps

Heat pump indoor unit

Heat pump outdoor unit

Heat pump vapor line temperature

Where possible, separate power of furnace fan

Gas furnaces

Gas furnace state (on/off); indicate if system in first or second stage by monitoring status of gas valve circuit (separate control circuit wire for each stage). Gas usage determined by clocking meter for each stage and also measuring combustion efficiency for each stage. Will not include modulating gas burners.

Where possible, separate power of furnace fan

PowerScout
Logging
interval

Logging

Device

Dent

PowerScout

Obvius

Acquisuite

5 minutes

(

kVAR, volts
PowerScout

AcquiSuite

5 minutes

PowerScout

AcquiSuite

5 minutes

Veris

temperature

sensor

PowerScout

AcquiSuit

5 minutes

kW, kWh, kVa kVAR, volts

Veris state

sensor

AcquiSuite

5 minutes

Cumulative and per-period use; duty cycle

Dual fuel systems: Combine above approaches 


\section{Water heat}

\begin{tabular}{|c|c|c|c|c|}
\hline Electric water heaters & PowerScout & AcquiSuite & 5 minutes & $\begin{array}{l}\mathrm{kW}, \mathrm{kWh}, \mathrm{kVa}, \\
\text { kVAR, volts }\end{array}$ \\
\hline $\begin{array}{l}\text { Gas water heater state (on/off); indicate status via } \\
\text { thermocouple in exhaust. Measure combustion } \\
\text { efficiency (one-time test). Will not include } \\
\text { modulating gas burners. }\end{array}$ & & AcquiSuite & 5 minutes & $\begin{array}{l}\text { Cumulative and } \\
\text { per-period use; } \\
\text { duty cycle }\end{array}$ \\
\hline \multicolumn{5}{|l|}{ Temperature } \\
\hline Indoor temperature (main living area) & $\begin{array}{l}\text { Onset } \\
\text { temperature } \\
\text { datalogger } \\
\text { (Pendant) }\end{array}$ & N/A & Hourly & $\begin{array}{l}\text { Average per } \\
\text { logging period } \\
\text { Downloaded at } \\
\text { the end of the } \\
\text { annual metering } \\
\text { period. }\end{array}$ \\
\hline Outdoor temperature & $\begin{array}{l}\text { Veris outdoor } \\
\text { temp sensor }\end{array}$ & AcquiSuite & 5 minutes & $\begin{array}{l}\text { Average per } \\
\text { period }\end{array}$ \\
\hline \multicolumn{5}{|l|}{ Appliances } \\
\hline Refrigerator & Wattsup & $\begin{array}{l}\text { Caching } \\
\text { server }\end{array}$ & 5 minutes & $\begin{array}{l}\mathrm{kW}, \mathrm{kWh} \\
\text { power factor }\end{array}$ \\
\hline Dishwasher (if on dedicated circuit) & PowerScout & AcquiSuite & 5 minutes & $\begin{array}{l}\mathrm{kW}, \mathrm{kWh}, \mathrm{kVa} \text {, } \\
\text { kVAR, volts }\end{array}$ \\
\hline Freezer & WattsUp & $\begin{array}{l}\text { Caching } \\
\text { server }\end{array}$ & 5 minutes & $\begin{array}{l}\mathrm{kW}, \mathrm{kWh} \text {, } \\
\text { power factor }\end{array}$ \\
\hline Clothes washer & WattsUp & $\begin{array}{l}\text { Caching } \\
\text { server }\end{array}$ & 5 minutes & $\begin{array}{l}\mathrm{kW}, \mathrm{kWh} \text {, } \\
\text { power factor }\end{array}$ \\
\hline Clothes dryer & PowerScout & AcquiSuite & 5 minutes & $\begin{array}{l}\mathrm{kW}, \mathrm{kWh}, \mathrm{kVa}, \\
\text { kVAR, volts }\end{array}$ \\
\hline Well pump & PowerScout & AcquiSuite & 5 minutes & $\begin{array}{l}\mathrm{kW}, \mathrm{kWh}, \mathrm{kVa} \text {, } \\
\text { kVAR, volts }\end{array}$ \\
\hline Spa & PowerScout & AcquiSuite & 5 minutes & $\begin{array}{l}\mathrm{kW}, \mathrm{kWh}, \mathrm{kVa}, \\
\mathrm{kVAR} \text {, volts }\end{array}$ \\
\hline
\end{tabular}


Other major appliances of interest

Plug loads

TVs

Set-top boxes

Gaming consoles

Other TV accessories

Computers

Computer peripherals

Window $\mathrm{A} / \mathrm{C}$ units

Space heaters

Lights

Average of 20 fixture groups per home

WattsUp/Pow-
erScout
depending on
wiring

Caching
server or
AcquiSuite

5 minutes

AcquiSuite
$\mathrm{kW}, \mathrm{kWh}$ power factor if on WattsUp; $\mathrm{kW}, \mathrm{kWh}, \mathrm{kVa}$, kVAR, volts if on

PowerScout

kW, kWh, power factor server

$\begin{array}{llll}\text { WattsUp } & \begin{array}{l}\text { Caching } \\ \text { server }\end{array} & 5 \text { minutes } & \begin{array}{l}\mathrm{kW}, \mathrm{kWh} \text {, power } \\ \text { factor }\end{array} \\ \text { WattsUp } & \begin{array}{l}\text { Caching } \\ \text { server }\end{array} & 5 \text { minutes } & \begin{array}{l}\mathrm{kW}, \mathrm{kWh} \text {, power } \\ \text { factor }\end{array} \\ \text { WattsUp } & \begin{array}{l}\text { Caching } \\ \text { server }\end{array} & 5 \text { minutes } & \begin{array}{l}\mathrm{kW}, \mathrm{kWh} \text {, power } \\ \text { factor }\end{array} \\ \text { WattsUp } & \begin{array}{l}\text { Caching } \\ \text { server }\end{array} & 5 \text { minutes } & \begin{array}{l}\mathrm{kW}, \mathrm{kWh} \text {, power } \\ \text { factor }\end{array} \\ \text { WattsUp } & \begin{array}{l}\text { Caching } \\ \text { server }\end{array} & 5 \text { minutes } & \begin{array}{l}\mathrm{kW}, \mathrm{kWh}, \text { power } \\ \text { factor }\end{array} \\ \text { WattsUp } & \begin{array}{l}\text { Caching } \\ \text { server }\end{array} & 5 \text { minutes } & \begin{array}{l}\mathrm{kW}, \mathrm{kWh}, \text { power } \\ \text { factor }\end{array} \\ \text { WattsUp } & \begin{array}{l}\text { Caching } \\ \text { server }\end{array} & 5 \text { minutes } & \begin{array}{l}\mathrm{kW}, \mathrm{kWh}, \text { power } \\ \text { factor }\end{array}\end{array}$

Lighting logger N/A 


\section{Selection Strategy}

HVAC, water heat, and appliances on dedicated circuits will be metered at all sites using current transformers installed at the main panel.

Refrigerators and clothes washers (when they are not on dedicated circuits) will be metered with the WattsUp.NET meter. At least the primary television and some accessories will be metered; at least the primary desktop computer(s) and some accessories will be metered.

Plug loads will be metered in the following priority:

- The primary television

- The set top device associated with the primary television

- The primary home office including a computer and as many peripherals as possible with one WattsUp?

- Remaining WattsUp? meters will be used to meter additional miscellaneous plug loads in the following priority:
- Room AC
- Freezer
- Additional refrigerator
- Additional TV
- Space heater

We have budgeted for an average of 8.6 plug meters per home for appliances and plug loads. Using the selection strategy above, the installers will meter as many appliances and plug loads as possible with 8.6 meters per home.

Lighting fixture on-time will be measured with stand-alone time of use (TOU) luminance meter/ dataloggers from Dent Engineering. These will be installed directly on or near fixtures; in some cases, a small, flexible fiber-optic "wand" will be used to improve measurement resolution.

Lights will be grouped into fixture groups and room types. These groupings will be determined using the Basic RBSA lighting audit, which assesses room-by-room lighting power, fixture groups, lamp types, and lighting controls. At the most basic level, a "fixture group" consists of all the lights on a single control. For example, a free-standing lamp with a built-in switch would be one fixture group; three ceiling lights on one switch would be one fixture group.

Based on the first 450 completed RBSA lighting audits, we conclude that 20 lighting loggers would cover about $80 \%$ of the room/fixture combinations. The RBSA lighting audit compiles the lighting

characteristics in each room of a home. For each fixture type, lamp type, and switching type, a separate lighting wattage is calculated. For this basic audit individual fixture groups are documented, as well as the total lighting power in each room. The Basic RBSA audit would be expanded for the metering project:

- The homeowner would be queried about the use patterns in the most complex rooms (e.g., living rooms with switchable task lights). 
- The auditor will be asked to document the placement of the loggers with respect to the total wattage metered.

- The auditor would identify the non-metered circuits and the amount of lighting power not metered in each room.

- These non-metered circuits could include notes when added information from the occupant is relevant to the interpretation of the logger data.

- A similar level of detail would be collected in rooms that are not logged.

It is important that the lighting power that is logged be as close to the true lighting as possible. This means that unoccupied rooms and very lightly-used areas would be avoided even if those areas represent a large fraction of the total lighting power. By prioritizing the metering in this way, overall runtime of the lighting can be inferred.

Primary Lighting Metering Targets

- Living room fixture group 1

- Dining room fixture group 1

- Family room fixture group 1

- Kitchen fixture group 1

- Master bedroom fixture group 1

- Each bedroom primary fixture group (up to three occupied bedrooms)

- Each bath primary fixture group (up to two occupied bath rooms)

- Main hall fixture group 1

- Other hall fixture group 1

- Office fixture group 1

- Basement (other) fixture group 1

- Closet (typical bedroom)

- Garage (typical

- One Exterior fixture group (as weatherproofing allows)

Additional fixture groups will be metered as possible in the following priority:

- Other frequently-used lights

- Unfinished basement

- Additional living room fixture groups

- Additional family room fixture groups

- Additional bathroom fixture groups

- Laundry room fixture group 1

- Additional bedroom fixture group

- Additional hallway fixture groups 



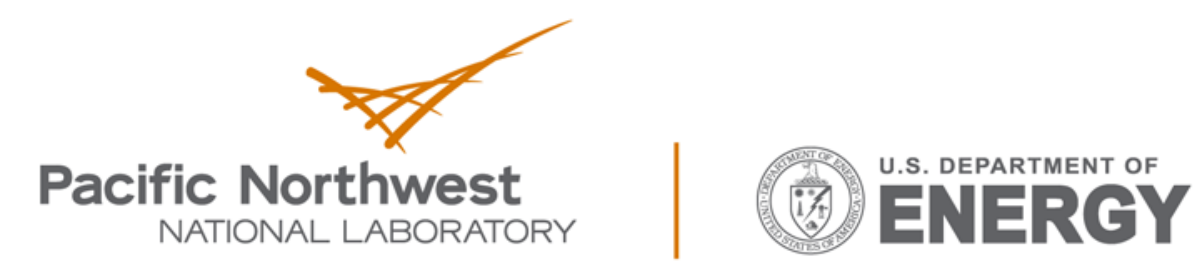

Proudly Operated by Battelle Since 1965

902 Battelle Boulevard

P.O. Box 999

Richland, WA 99352

1-888-375-PNNL (7665)

www.pnnl.gov 